\title{
Egipto y Gran Bretaña
}

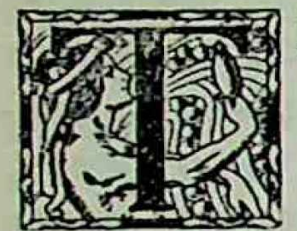

RAGICO ha sido el destino del noble Eggipto. Tierra hermosa y próvida donde floreció una de las más antiguas civilizaciones, tierra de monumentos milenarios, testimonios, al parecer eternos del poder del espiritu humano encarnado en la raza egipcia, ha sido desde la antigüedad pisoteada por pueblos invasores, conquistadores y explotadores.

A la riqueza maravillosa de su suelo y a su posición geográfica en el centro del mundo antiguo, en el cruce del Asia, del Africa y de Europa, habría que señalar como principales antecedentes de ese curso de la historia del Egipto.

Después de largos siglos de supremacía en el Africa y de brillo independiente y autónomo, el Eggipto fué sometido sucesivamente en los tiempos antiguos por los asirios, los persas, griegos y romanos. Luego en la Edad Media fueron sus amos los bizantinos y los árabes, y ha vivido todos los siglos de la época moderna, sometido a la dominación turca.

En la primera mitad del siglo XIX bajo la administración progresista y llena de iniciativas del intrépido bajá Mehemet-Ali llegó a formar un reino virtualmente independiente de la Turquia.

La nueva grandeza del Egipto alcanzó su apogeo con la apertura del canal de Suez en 1869. Pero en esta obra de progreso hay que buscar otra de las causas de los posteriores quebrantos y perturbaciones del país del Nilo. Inglaterra habia visto desde el primer momento con suspicacia y desconfianza que esa grande empresa se fuera a llevar a cabo por un francés: $M$. de Lesseps, y bajo la protección de la Francia. Temía las complicaciones que el canal, no siendo suyo. pudiera traerle para su imperio en la India y. hasta donde pudo. trató de impedir su construcción. A la inauguración oficial de la vía concurrieron la Emperatriz de los franceses, el Emperador Francisco José de Austria, el príncipe real Federico de Prusia, el principe y la princesa de los Paises Bajos. Ciento treinta buques. llevando los pabellones de todos los países europeos, hicieron la travesía del canal. En estas solemnes festividades el gobierno inglés no se hizo representar.

Luego la mala administración y la dilapidaciones del Kedive Ismail-Bajá trajeron grandes dificultades financieras que pusieron al país al borde de la bancarrota. El bajá no encontró quien le prestara el dinero que necesitaba tanto para sus gastos como para pagar a sus numerosos acreedores. En 1873 ofreció en venta sus acciones del canal al gobierno francés; pero éste no las aceptó. En cambio el gobierno inglés las compró secretamente por cien millones en 1875 . Desde este momento tuvo tanto derecho como la Francia para intervenir en el pais y la intervención vino.

Los gobiernos francés e inglés obligaron a Ismail-Bajá a admitir dos con- 
froladores de la administración pública, con lo que se estableció el condominio financiero de Francia e Inglaterra.

La intervención de los extranjeros, las economias introducidas en el presupuesto y, entre éstas, la disminución del número de oficiales del ejército y la rebaja de sus sueldos provocaron un violento movimiento nacionalista que revistió caracteres de gravedad desde 1879 y culminó en el estallido de 1882.

Fué un movimiento en que se mezclaron como resortes el amor a la libertad la protesta contra la opresión extranjera y el fanatismo religioso de los mulsumanes. Su reconocido conductor lué Arabi-Bajá, que desempeñaba el carģo de Ministro de la Guerra.

En Alejandría hubo matanzas de europeos y saqueos de sus casas. Arabi empezó a levantar fortificaciones alrededor de la plaza para rechazar todo ataque de las escuadras francesa e inglesa fondeadas en el puerto. El gobierno inglés invitó al gobierno francés a dirigir conjuntamente un ultimátum a los egipcios a fin de que suspendieran sus obras de defensa. El gobierno francés no se creyó con derecho para dar este paso y su escuadra se retiró de Alejandría. Los ingleses bombardearon solos el puerto, destruyeron todos sus fuertes, y luego. dando la vuelta por el canal de Suez, el general Wolseley entraba triunfante en El Cairo. El Eģipto pasaba a ser una colonia del Imperio Británico.

¿Como no rendir un homenaje a la noble actitud de la Francia? Con estos gestos desinteresados de respeto al derecho de los pueblos, y sólo así, se conquista la gloria de poder ser llamada tierra del idealismo. sTome quien quiera. ha dicho M. James Darmesteter, el monopolio de explotar el Egipto de hoy y de despojar a los fellahs; el Egipto, por sus cuarenta siglos de historia, pertenece a la Francia gracias al genio de Champollion y de Mariette y a la abnegación cientifica de Maspero.

El Egipto había perdido su independencia por no haber pagado sus deudas.

Este hecho prueba que el denominado derecho Internacional se hallaba entonces en ese estado de bárbaro atraso en que se encontraba el derecho civil hace dos mil cuatrocientos años al tiempo de la promulgación de las leyes de las Doce Tablas.

En esa época al deudor que no pagaba se le podia reducir a la esclavitud y aún descuartizar.

Hace más de dos mil años que esas disposiciones fueron abolidas. Hoy no se comprenderia que a un individuo se le redujera a prisión por deudas; pero se acepta como lo más natural de la vida que a un pueblo por la misma razón se le esclavice.

¿Hay en estos diferentes procederes alguna razón de garantía o una justa sanción para quien no cumple sus compromisos?

¿Qué garantía existe respecto de la cancelación de las deudas individuales 
ahora que no es posible reducir a prisión a los deudores morosos ni aún confiscarles los sueldos, como ocurre entre nosotros?

Una muy sencilla, la de no prestarle a quien no inspira confianza, a aquel de quien se teme que resulte insolvente. ¿Por qué no se podria aplicar el mismo procedimiento a los pueblos? Nos imaginamos que sería aún más lácil que en el caso de los individuos. Se sabe de una manera tan precisa cuando un pueblo se encuentra en mala situación financiera o no es serio en el cumplimiento de sus compromisos. Y cuanto se mejoraría la situación de muchos estados con que sólo se les cerraran las puertas del crédito exterior.

Pero de esta suerte los grandes financieros no podrian hacer negocio e hincar sus garras en los pueblos económicamente atrasados y los gobiernos de las potencias poderosas y ricas se solidarizaran con sus financieros.

Durante la gran guerra europea flamearon de parte de los aliados altísimos ideales de libertad, de humanidad y de democracia, como antítesis de los principios contrarios que informaran según se decía. los anhelos de los imperios centrales. Se encendió en verdad una llamarada de idealidad que arrastró a los pueblos a luchar contra las imposiciones de la fuerza y del militarismo.

El Presidente Wilson condenó esas nobles finalidades en sus catorce puntos, entre los cuales se destacaba el de la auto-determinación de los pueblos débiles y pequeños. Todos los pueblos serian independientes y soberanos dentro de la solidaridad de la sociedad de las naciones. Hermoso ideal.

El pueblo egipcio. obtuvo en 1922 una especie de autonomia; pero al parecer, ha estado muy lejos de significar en realidad la independencia a que tiene derecho. Los nacionalistas, cuyo jefe más caracterizado es el hábil Zaghlud Bajá, no han quedado satisfechos. La Inglaterra se ha reservado una amplia intervención en los asuntos del país.

Fruto del descontento y obra de los más exaltados fué sin duda el asesinato de Sir Lee Stack.

Con este motivo Gran Bretaña ha impuesto al Egipto sanciones y condiciones que muchos órganos de la prensa europea no han vacilado en calificar tan duras y brutales, tan inaceptables para un pueblo libre, como el ultimátum que Austria enviara a Servia en 1914 después del asesinato de los archiduques. Los conservadores ingleses, hoy en el poder. han rechazado perentoriamente hasta ahora la intervención de la Liga de las Naciones en el asunto. Según ellos sería esta una cuestión que le tocaría resolver sólo a Inglaterra. El Egipto es un pueblo sometido y ella tiene la fuerza.

¿En que han quedado los ideales de los aliados, los ideales de la libertad y la autodeferminación de los pueblos pequeños?

¿En que ha quedado la lucha contra el imperio de la fuerza y el militarismo? 
Así, negado el derecho y la justicia, se siembra el escepticismo desmoralizador de cuya acción deletérea protestan después los poderosos. Y no se olviden de que el escepticismo, que en el organismo social puede traer el desorden y la anarquía, principia por ser siempre el primer disolvente, vengador de la justicia hollada y destructor de los regímenes de iniquidad.

E. $M$. 